DOI https://doi.org/10.30525/978-9934-26-180-0-37

\title{
THE PRACTICAL APPROACHES TO WRITTEN TRANSLATION TEACHING PROCESS
}

\author{
Hrytsanchuk O. O. \\ Candidate of Philological Sciences \\ Associate Professor at the Department Foreign Languages \\ Educational and Scientific Institute of International Relations \\ Taras Shevchenko National University of Kyiv \\ Kyiv, Ukraine
}

Modern research in Translation studies should correspond with the needs of nowadays education process. This paper is emphasized that the demands on translation practitioners are to serve the needs of students and professionals to conduct their studies, research, and business in English on an international scale; optimize translation studies learning process and give ESL students confidence in making their translation decisions. Interconnected three-semester course in theory and practice of translation for third and fourth -year students of the department of International Relations is under consideration. Group meets twice a week and targets the acquiring translational skills. Before performing practical assignments translating from English into Ukrainian and vice versa class is provided with lectures covering main issues in Translation Studies [2]. Typical practical written translation courses are of the following structure: tasks to speak on the topic of the text; words/terms study which are the stem of the text; key words to understand the parts and whole text; tasks to understand the main idea; tasks to read the text in the following order: word, sentence, paragraph, text; after text tasks include detailed lexical analysis, grammatical difficulties. It's important to study lexico-grammatical and syntactical difficulties of the text in more complicated and precise way with every lesson, step by step, from simple to complex. Evaluation of the translation may be done on the following principles: pragmatic norms of translation; equivalent norms of translation; absence of contextual, cultural, functional, lexico-grammatical mistakes.

In order to archive text translated adequately students of International Relations (or future translators) should use regular correspondences between two languages properly, and overcome difficulties in case of irregular transformations due to structural and/or semantical differences between languages under consideration. Translation without transformation possible but in rare cases: only when we have direct correspondences without inner or hidden sense or intension («between lines sense» in case of idiomatic expressions, 
neologisms, buzz words and alike), even direct word order, syntactical connection between words in the sentence is clear and close to English sentence. Based on my experience translation is impossible without grammatical transformations, changes in word order and substitutions of any kind syntactical or morphological. According to my experience only predicate transformations may form sentence mirroring (which corresponds) source sentence stylistically and grammatically. Comparative on grammatical/syntactical level research results may reveal could we preserve the identical grammatical forms. Such analytical work gives us confidence about making a decision of formal equivalence in translation, advisability (expedience/y) regularity of formal transformations of any kind. Such translation decisions also include stylistic factor. When we consider questions concerning grammatical issues of translations leading role play requirements for preserving (saving) meaning due to its connection with forms elements, their sense role determined by connections with text itself and influence to the choice language means; for other hand we take into consideration target language norms. Impossibility of finding grammatically identical units and as a result impossibility fully correspond meaning is always compensated using other appropriate grammatical or dictionary means. In some cases, inability without general context make translation decision means that keeping in mind systems of language means is a must. Separated elements or elements of language system separated accidently sometimes impossible to translate

It's essential to clarify the interconnection between translation equivalents and adequacy. It's worth mentioning the notion of exactness, which has nothing to do with simple copy of the original text by means of target language, even more, text style, exactness; genre are adequate translation features. Adequate translation is characterized by precise correspondence, exactness of the meaning, style, genre, correspondence with norms of target language. Due to the fact that adequacy requirements are optimal translation may have considered as adequate even when the text of translation is equivalent to the source text on one of the semiotic levels or in functional levels. Equivalent translation is a translation done one of the levels of adequacy. The choice of the translation levels is, actually, a strategy of written translation which is fulfilled while analyzing the text.

Active reading to fully understand the text, especially those parts which may be difficult from the grammatical, lexical, stylistic or pragmatic point of view, make necessary research. Pre-translation stage includes reading for comprehension, identifying main ideas, target audience, translator's problems (difficulties): terminology and grammar peculiarities. Pre-translation analysis of the text: a) documentary research - study of any valuable extra-linguistic 
information; b) comprehending the writer's intention and main message; c) text organization analysis (logical connectives, cause and effect relations); d) search of translation equivalents; e) focus on the stylistic aspects of the text (genre, register, stylistic devices); 1) deciphering and adaptation of units of measure, abbreviations, proper names [1, p. 11-13].

Lexical, morphological, syntactical, usage and stylistic differences between verb forms in English and Ukrainian are main causes of predicate transformations in particular and translating transformation in general. Any grammatical forms undergo translating transformations, including those having in other general or immediate contexts direct correspondents. Full or partial equivalent (meaning or grammatical forms, constructions) also requires grammatical transformations to be applied. There are partial coincidence of passive constructions, partial coincidence infinitive forms, differences in modality. We use predicate transformations due to communicative, stylistic, grammatical, semantical and blended types reasons.

Trying to apply strict translating transformations rules in the process of study, we should remember that translation is very complicated analytical work; each text is unique and many factors may influence to our word choice. Objective evaluation training translation texts is of a vital importance for forming professional competence for future specialists in international relations. Evaluation should be based on measuring correspondence degree of all text features of target text to authors intensions of source text. There are different methods for evaluating training texts of translation from subjective criterions such as correctness, natural (all target text norms and forms correspondence) feeling of target text, faithfulness to attempts of objectiveness rising. In case when student realize gap between languages it's possible to use technical translator's devices in correspondence with defined contradiction norms. At practice and theory translation classes our aim is to identify methodologically proved criterions. As for conveniences of the process of evaluation we may stick on concreteness and simplicity finding in the sentence translations mistakes. Criterions may be the following: 1) simplicity without strict rules and simultaneously not to be so splitting (embranchment). Translation is unique in each case, it should be evaluated with care and «game rules» (examples, translation mistakes description) should be known for both sides; 2) objectiveness. Our aim as facilitators in gaining knowledge process to minimize subjectiveness; 3) be in trend with modern translation studies as applied as pure theoretical achievements.

Students are accustomed to read English text word for word rather than analyzing professionally oriented texts with the purpose to translate them into native language. It's preferable to give students short vocabulary list, 
exercises for matching tasks, ask them to translate sentences containing translation difficulties, discuss and solve translator's problems. On the second stage the process of translation includes analytic and variation search of the professional texts.

Students must complete exercises to demonstrate they can identify, understand, and analyze the use of these elements on the first stage of translational work. In many cases this requires use of dictionary. Indeed, after a period in which research in computer translation seemed to have foundered, the importance of the relationship between translation and the new technology has risen to prominence and shows every sign of becoming even more important in the future.

Analytical approach to the training texts/assignments for translation process, cultural background of source language country custom and traditions, understanding subject area and issues related to source text, ability to analyse text from different point of view: cultural, philosophical, political definitely give confidence in making translation decisions. Main requirements for students usually include ability to perform lexical and syntactical text analysis; identify informational constituents/ communicative-pragmatic functions of the text; correct text segmentation into units of translation in order to find proper equivalent; ability to achieve functional and stylistic adequacy correctly identifying regular correspondences and identifying terminology.

\section{References:}

1. Burak, A.L. Translating Culture: Translation and cross-cultural communication. Stage1: Words. Moscow, Russia: R.Valent, 2002. P. 11-13.

2. Miram G. and others (2002) Basic Translation. A course of lectures on translation theory and practice for institutes and departments of international relations. Kyiv: Elga nika-Center, 2002. 240 p.

3. Velykodska $\mathrm{H}$. The application of translation strategies in written translation teaching process. Вісник національного технічного університету України «Київський політехнічний інститут», Серія: Філологія, Педагогіка. К.: «Політехніка», 2015. Вип. 5, С. 45-51 